\title{
Graphic tobacco warning labels - an improper solution?
}

This article was published in the following Dove Press journal:

Lung Cancer:Targets and Therapy

12 July 2014

Number of times this article has been viewed

Joshua D Salvi

Weill Cornell Medical College, New York, NY, USA
Correspondence: Joshua D Salvi Weill Cornell Medical College, 445 East 69th Street, New York, NY 10021, USA

Email jds2005@med.cornell.edu
In June 2009, President Barack Obama signed into law the Family Smoking Prevention and Tobacco Control Act (HR 1256). This legislation required that all tobacco products and advertising must have a graphic warning covering 50 percent of the front and back of the package. The US Food and Drug Administration (FDA) has proposed a number of graphic designs, and the final designs were submitted in June, 2011. The proposed designs include grotesque imagery in an attempt to dissuade smoking in the USA. However, these graphic labels were invalidated in court due to violation of freedom-of-speech rights. Independent from that point, these labels, if appealed, would do more harm than good from a public health perspective. According to the Centers for Disease Control, smoking accounts for approximately 443,000 deaths per year in the USA, including deaths from lung cancer, cardiovascular disease, chronic obstructive pulmonary disease, and numerous other morbidities. It is thus apparent that smoking is a public health concern, and these new warning labels hope to address the concern by deterring such behavior. However, although such graphic labels may be more effective than the previous Surgeon General's warning (a text-only message on the side of the package), they can be greatly improved through what is defined as a gains-based message as opposed to the proposed loss-based message. In doing so, the labels would not only educate the public on the dangers of smoking, but they would effectively encourage smoking prevention and cessation behavior. Indeed, the currently proposed labels may do more harm than good. To make this argument, three assumptions are necessary. First, as hinted above, smoking is a public health concern. Second, tobacco warning labels are designed to result in human behaviors of smoking cessation and prevention. Finally, human behavior is, in some circumstances, predictable.

This is not to say that the labels proposed by the FDA or those currently being used around the world are completely ineffective. In fact, the graphic labels may be more effective than the small text-only Surgeon General's warning. However, there is a wide margin for improvement. The proposed labels appear to be far too grotesque. Though admittedly fear-inducing, this negative emotion will most likely lead to reactance behavior. Expect sales of slip covers to increase, along with the possibility of some smokers increasing their smoking behavior. Smoking rates may continue to decline, but the rate of this decline may not yet be optimal. Data from other countries, along with numerous experimental studies, have demonstrated that confounding factors can 
contribute to the decline in these countries, and grotesque imagery can result in maladaptive behavior. A truly effective label would be designed with a positive, gain-framed message. It would be designed to motivate behavioral change and encourage self-efficacy. Data from others who were able to quit can enhance subjective norms. Imagery depicting the benefits of quitting or those who were able to quit can further eliminate reactance. All of this would then be coupled with resources on quitting, such as phone numbers, web sites, and support groups. This is a war that cannot be fought with fire. As demonstrated every time a cigarette is lit, fire is only good for lighting up.

\section{Disclosure}

The author reports no conflicts of interest in this work.

\section{Publish your work in this journal}

Lung Cancer: Targets and Therapy is an international, peer-reviewed, open access journal focusing on lung cancer research, identification of therapeutic targets and the optimal use of preventative and integrated treatment interventions to achieve improved outcomes, enhanced survival and quality of life for the cancer patient. Specific topics covered in the journal include: Epidemiology, detection and screening; Cellular research and biomarkers; Identification of biotargets and agents with novel mechanisms of action; Optimal clinical use of existing anticancer agents, including combination therapies; Radiation and surgery; Palliative care; Patient adherence, quality of life, satisfaction; Health economic evaluations. The manuscript management system is completely online and includes a very quick and fair peer-review system. Visit http://www.dovepress.com/testimonials.php to read real quotes from published authors. 